\title{
Aerosol Characteristics over the Northwestern Indo-Gangetic Plain: Clear-Sky Radiative Forcing of Composite and Black Carbon Aerosol
}

\author{
Onam Bansal, Atinderpal Singh, Darshan Singh* \\ Department of Physics, Punjabi University, Patiala, Punjab, India
}

\begin{abstract}
The present study examines the aerosol characteristics over Patiala in northwestern India from October 2013 to June 2014. The average mass concentration of the total suspended particulates (TSP) varied from 117 to $301 \mu \mathrm{g} \mathrm{m}^{-3}$, with $\mathrm{PM}_{10}$ accounting for $\sim 63-83 \%$ from October to February (P1) and decreasing to less than $\sim 40 \%$ from March to June (P2). The aerosol optical depth $\left(\mathrm{AOD}_{500}\right)$ exhibited its highest values during October (0.818) and its lowest during April (0.332), with the wavelength dependence differing significantly on a temporal scale. The Ångstrom exponent $\left(\alpha_{380-870}\right)$ values indicated a relatively high quantity of fine-mode particles over the study region during $\mathrm{P} 1$ as compared to $\mathrm{P} 2$, which is consistent with the PM measurements. The average monthly mass concentration of the climate forcing agent black carbon (BC) varied from 2.4 to $12 \mu \mathrm{g} \mathrm{m}^{-3}$, with the highest mass concentration in December and the lowest in June. The average monthly single scattering albedo $\left(\mathrm{SSA}_{500}\right.$ ) derived from the OPAC (Optical Properties of Aerosols and Clouds) model varied from 0.890 to 0.947 , with lower values during P1 than P2. The average monthly clear-sky direct atmospheric aerosol radiative forcing (ATM ARF) estimated by the SBDART (Santa Barbara DISORT Atmospheric Radiative Transfer) model ranged between +12 and $+36 \mathrm{Wm}^{-2}$ over the study region. Even though the mass fraction of $\mathrm{BC}$ averaged over the study period was only $2.4 \%$ of the total mass of the composite aerosol, its contribution to net ATM ARF was found to be significant $(>60 \%)$, indicating that $\mathrm{BC}$ contributes significantly to warming on a regional scale. These results improve our understanding of the impact of $\mathrm{BC}$ and composite aerosol on the earth's radiation budget and hence on regional climate.
\end{abstract}

Keywords: Biomass burning emission; Particulates; Aerosol optical depth; Single scattering albedo; Aerosol radiative forcing.

\section{INTRODUCTION}

Global climate is regulated by the balance between incoming and outgoing solar radiation in the earth's atmosphere. Perturbation in the earth's radiation budget due to natural processes and anthropogenic activities has significant implications to the climate change. Among various factors that are responsible for the climate change, the role of atmospheric aerosol is highly uncertain (IPCC, 2013). Aerosol affects the earth's radiation budget directly by scattering and absorbing the incoming solar radiation and indirectly by acting as cloud condensation nuclei (CCN). Due to inadequate knowledge of spatio-temporal variations in the aerosol characteristics along with inaccuracy in the estimation of their radiative forcing at regional and global scale lead to large uncertainties in estimation of the climate perturbation. Indo-Gangetic Plain (IGP) being hot spot for

\footnotetext{
* Corresponding author.

Tel.: +91-98720 12766

E-mail address: darshan@pbi.ac.in
}

aerosol research due to diverse emission sources and unique topography; intensive studies have been made over this region on aerosol characterization and their effect on regional climate and air quality (Lau et al., 2006, and references therein; Singh et al., 2015; Rastogi et al., 2016). The northwestern part of IGP is affected by large-scale paddy residue burning during autumn (Kaskaoutis et al., 2014; Rastogi et al., 2014; Singh et al., 2016a) and wheat residue burning during summer (Rajput et al., 2011; Rastogi et al., 2016) every year, and also influenced by occasional dust storms during April to June (Sharma et al., 2012a; Singh et al., 2015). During winter, prevailing meteorological conditions over this region are favorable for the formation of haze and fog for most of the days (Tare et al., 2006; Rastogi et al., 2015). In general, the atmospheric aerosol loading over Patiala is high from October to June except March to April (Singh et al., 2016a). Earlier studies of aerosol characterization over Patiala (Sharma et al., 2012b; Kant et al., 2015, Singh et al., 2016b) pertains to radiative properties of composite aerosol for short durations and that too for specific events. However, radiative properties of $\mathrm{BC}$ aerosol and their contribution to net forcing have not been examined so far over the study region. The present 
study is focused on estimating the direct atmospheric radiative forcing pertaining to $\mathrm{BC}$ aerosol and composite aerosol separately during October 2013 to June 2014 over Patiala. Present research work may enhance our knowledge on radiative properties of composite as well as $\mathrm{BC}$ aerosol during different seasons over the study region that are crucial in the context of regional climate change.

\section{SITE DESCRIPTION AND METEOROLOGY}

The sampling site Patiala $\left(30.33^{\circ} \mathrm{N}, 76.40^{\circ} \mathrm{E} ; 250 \mathrm{~m}\right.$ above mean sea level) is located in the northwestern part of Indo-Gangetic Plain (IGP), a region ranked among the world's most densely populated areas. The study region is surrounded by the unique topography with Himalayan range of mountains to the north and Thar Desert is about $300 \mathrm{~km}$ away in the southwest. Patiala is a semi-urban city with no major industries and surrounded by vast agricultural fields. Big industrial cities like Ludhiana, Mandi Gobindgarh and Amritsar are located in the northwest direction (within $\sim 50-200 \mathrm{~km}$ ) of Patiala. More details of site description and prevailing emission sources have been provided in our earlier publications (Rastogi et al., 2014; Singh et al., 2014). Various meteorological parameters used in the present study were procured from meteorological observatory of Indian Meteorological Department (IMD) situated near the sampling site in the Punjabi University campus and are summarized in Table 1.

\section{DATASETS AND METHODOLOGY}

Aerosol samples were collected using high volume air sampler (Envirotech, RDS) that fractionate the suspended particulate matter into respirable (RSPM; $\mathrm{PM}_{10}$ ) and nonrespirable fraction (NRSPM; $>\mathrm{PM}_{10}$ ) and mass concentration of these samples was determined gravimetrically. The measurements of spectral aerosol optical depth (AOD; 380, 440, 500, 675 and $870 \mathrm{~nm}$ ) have been made using MICROTOPS-II (MT) sunphotometer (Morys et al., 2001). For more details about the AOD measurements, refer to our earlier publications (Singh et al., 2015, 2016c). The overall uncertainty in AOD measurements does not exceed 5\% (Kedia and Ramachandran, 2011). The atmospheric black carbon (BC) concentration was monitored online using an Aethalometer (AE-31, Magee Scientific, USA). It measures optical attenuation (absorbance) of light at seven wavelengths $(370,470,520,590,660,880$, and $950 \mathrm{~nm})$ with a typical half-width of $20 \mathrm{~nm}$ (Hansen, 2005). However, mass concentration obtained at $880 \mathrm{~nm}$ has been taken as measured $\mathrm{BC}$ concentration for the present study since among major aerosol species in the atmosphere, $\mathrm{BC}$ has maximum absorption at this wavelength. Over the observation site, direct measurements of optical properties like single scattering albedo, asymmetric parameter are not available and these are obtained by using Optical Properties of Aerosols and Clouds (OPAC) model (Hess et al., 1998) simulations by taking a mixture of five aerosol types (soot, water soluble, insoluble, mineral accumulation and mineral transport) as externally mixed spherical particles forming the composite aerosol. $\mathrm{BC}$ mass mixing ratio $(\% \mathrm{BC}$ to total mass) was fixed while the number densities of other components were varied. A number of iterations were performed till the estimated spectral AOD were in close agreement with the sunphotometer based measured values. For OPAC simulation, BC mass has been integrated for 09:00 to 17:00 IST to estimate their fraction to TSPM. More details of the procedure for simulating the optical properties of aerosol using OPAC software have been provided in our earlier publications (Sharma et al., 2012a; Singh et al., 2016c). In the present study, Santa Barbara DISORT Atmospheric Radiative Transfer (SBDART) model was used to estimate the direct aerosol radiative forcing (ARF) under clear-sky conditions in the short wave (SW) wavelength range of $0.25-4.0 \mu \mathrm{m}$ at the time interval of 15 minutes (Ricchiazzi et al., 1998). OPAC simulated spectral optical properties of composite aerosol (i.e., AOD, SSA, asymmetry parameter) along with surface albedo obtained from MODIS albedo product, columnar water vapor and columnar ozone was used as an input in SBDART model to compute the clear-sky direct short wave ARF. Based on the prevailing meteorological conditions over the study region, mid-latitude winter (October-February) and mid-latitude summer (MarchJune) model atmosphere was used in SBDART model (details are presented in Singh et al., 2016b, c). In addition, direct radiative forcing solely due to $\mathrm{BC}$ aerosol was derived by employing modeled $\mathrm{BC}$ optical properties in the SBDART model (Panicker et al., 2010). The atmospheric aerosol radiative forcing $\left(\Delta \mathrm{F}_{\mathrm{ATM}}\right)$ is further used to calculate the atmospheric heating rate in the lower atmosphere by employing the following equation (Liou, 2002):

Table 1. Variation of surface meteorological parameters \{temperature (Temp), relative humidity (RH) and wind speed (WS)\}, aerosol optical depth (AOD) and Ångström exponent (AE).

\begin{tabular}{llllll}
\hline Months & Temp $\left({ }^{\circ} \mathrm{C}\right)$ & $\mathrm{RH}(\%)$ & $\mathrm{WS}\left(\mathrm{m} \mathrm{s}^{-1}\right)$ & $\mathrm{AOD}_{500}$ & $\mathrm{AE}_{380-870}$ \\
\hline October & $27 \pm 3.8$ & $67 \pm 16$ & $2.1 \pm 1.2$ & $0.818 \pm 0.334$ & 1.0 \\
November & $22 \pm 4.7$ & $55 \pm 18$ & $2.3 \pm 1.0$ & $0.557 \pm 0.229$ & 1.0 \\
December & $17 \pm 3.8$ & $70 \pm 17$ & $2.4 \pm 1.3$ & $0.572 \pm 0.251$ & 1.1 \\
January & $15 \pm 3.0$ & $76 \pm 15$ & $3.0 \pm 1.8$ & $0.683 \pm 0.187$ & 0.9 \\
February & $19 \pm 3.3$ & $68 \pm 13$ & $1.5 \pm 0.8$ & $0.500 \pm 0.146$ & 1.1 \\
March & $22 \pm 4.9$ & $70 \pm 15$ & $3.0 \pm 2.0$ & $0.381 \pm 0.096$ & 0.7 \\
April & $27 \pm 6.7$ & $43 \pm 17$ & $1.9 \pm 1.0$ & $0.332 \pm 0.089$ & 0.5 \\
May & $31 \pm 5.0$ & $44 \pm 15$ & $4.3 \pm 3.0$ & $0.380 \pm 0.079$ & 0.9 \\
June & $35 \pm 5.3$ & $45 \pm 18$ & $2.0 \pm 1.1$ & $0.554 \pm 0.210$ & 0.5 \\
\hline
\end{tabular}


$\frac{\partial T}{\partial t}=\frac{g}{C_{p}} \frac{\Delta F_{A T M}}{\Delta P}$

where $\partial T / \partial t$ is heating rate (Kelvin per day), $g$ is the acceleration due to gravity, $C_{p}$ is the specific heat capacity of air at constant pressure and $\Delta P$ is the atmospheric pressure difference between top and bottom boundaries of the atmosphere in which most of the aerosol occur, taking $300 \mathrm{hPa}$ as the top boundary in the present study.

Accurate estimation of shortwave ARF can be affected by various factors such as assumptions made regarding choice of model atmosphere as well as OPAC simulations, error in measurements of AOD, BC mass concentration, surface albedo and molecular scattering absorption. OPAC simulated optical properties may also be influenced by other factors such as scale height and sky conditions, and consequently affect the direct ARF (Dey et al., 2008). Due to unavailability of the information about the scale height for individual species, forcing values were estimated by assuming similar scale height for all the species. The combined effect of these factors may result in overall uncertainty in ARF calculations not more than 15\% (Srivastava et al., 2011).

\section{RESULTS AND DISCUSSION}

\section{Variation in Mass Concentration of Particulate Matter and Black Carbon Aerosol}

During the observation period, monthly mean mass concentration of total suspended particulate matter (TSPM) varied from 117 to $301 \mu \mathrm{g} \mathrm{m}^{-3}$ with highest concentration during June and lowest during March (Fig. 1). In TSPM, the magnitude of RSPM and NRSPM ranged from 49 to $187 \mu \mathrm{g} \mathrm{m}^{-3}$ and 38 to $199 \mu \mathrm{g} \mathrm{m}^{-3}$, respectively. In nutshell, absolute mass concentration of TSPM is significantly high during October to January, and May to June as compared to rest of the study period. This trend can be attributed to large scale paddy residue burning during autumn (OctoberNovember) and, emissions from bio- and fossil fuel combustion during winter (December-February) as well as favorable meteorological conditions (cool to moderate climatic condition) with shallow boundary layer facilitating accumulation of particles near the surface during October to February. Occasional dust storm during April-June is responsible for higher concentration of particulates. The details of these prevailing emission sources are provided in the subsequent discussion. The fraction of RSPM to TSPM remains significantly high $(>60 \%)$ from October to February which decreases to the lowest value of $30 \%$ during April and remains low $(\sim 34-36 \%)$ during May to June. On the other hand, the fraction of NRSPM to TSPM shows the opposite trend with higher fractions $(\sim 58-70 \%)$ during March to June and lower fractions ( $\sim 17-37 \%)$ during October to February. The abundance of fine-mode aerosol during October to November is due to large-scale agricultural waste (paddy residue) burning emissions in the open fields by the farmers (Rastogi et al., 2016; Singh et al., 2016a). Remnants of agricultural waste burning emission and emissions from bio- and fossil fuel combustion along with shallow boundary layer is responsible for high fraction of finer aerosol during December to February (Rastogi et al., 2014; Singh et al., 2014). The fraction of coarser aerosol increases during March to June due to relatively dry atmospheric conditions in conjunction with relatively high wind speed favoring the uplifting of soil particles into the air. In addition, occasional dust storms also contributed to the loading of coarse-mode aerosol that occurs from April to June over the study region (Sharma et al., 2012a; Singh et al., 2015). However, during the first half of May month, wheat residue burning also takes place contributing a small increase in the fraction of RSPM from 30\% (April) to 36\% (May) but its contribution is much lower than paddy residue burning. This difference can be attributed to amount of agricultural waste burnt as the significant fraction of wheat residue is used for cattle feed while paddy residue is unfit for cattle feed (Sahai et al., 2007). In addition, relatively hot climatic conditions during May as compared to autumn also favor the dispersion of pollutants deep into the atmosphere. As mentioned earlier, emissions from largescale paddy residue burning and from bio- and fossil fuel combustion along with shallow boundary layer during winter led to high mass concentration $\left(5.6-12 \mu \mathrm{g} \mathrm{m}^{-3}\right)$ of climatic forcing agent $\mathrm{BC}$ during October to February (Fig. 2(a)). On the other hand, BC mass concentration ranged between 2.4 and $3.3 \mu \mathrm{g} \mathrm{m}^{-3}$ during March to June having maximum mass concentration during May and minimum during June. To identify the relative contribution of different emission sources to the loading of $\mathrm{BC}$ aerosol, the literature based approach has been adopted (Herich et al., 2011; Wang et al., 2011). This approach is based on the values of the ratio estimated by dividing the difference of $\mathrm{BC}$ mass concentrations measured at two different channels with $\mathrm{BC}$ measured at $880 \mathrm{~nm}$, i.e., (BC370-BC880)/BC880. The positive value of the ratio is an indicator for the dominant contribution of biomass burning emissions, whereas the negative value of the ratio suggests for the dominant contribution from fossil-fuel combustion sources. In the present study, around $\sim 77 \%$ of data point's exhibited positive values of the ratio indicating the overall dominance of biomass burning emission over the fossil fuel combustion during autumn (Fig. 2(b)). However, during winter season (December-February); this ratio oscillates between positive and negative values indicating the mixed contribution from bio- and fossil-fuel combustion as well as biomass burning emission to the ambient BC. During the month of June, ratio exhibit mostly negative values, suggesting an increase in the relative contribution of fossil-fuel combustion as compared to biomass burning to the $\mathrm{BC}$ loading.

\section{Optical Properties of Aerosol}

Aerosol loading affects the surface reaching solar flux by extinction of incoming solar radiation which is quantified in term of AOD. During the present study, monthly mean $\mathrm{AOD}$ at $500 \mathrm{~nm}\left(\mathrm{AOD}_{500}\right)$ exhibited highest magnitude $(0.818 \pm 0.334)$ during October and lowest magnitude $(0.332$ \pm 0.089 ) during April (Table 1). Spectral AOD exhibit relatively strong wavelength dependence from October to 


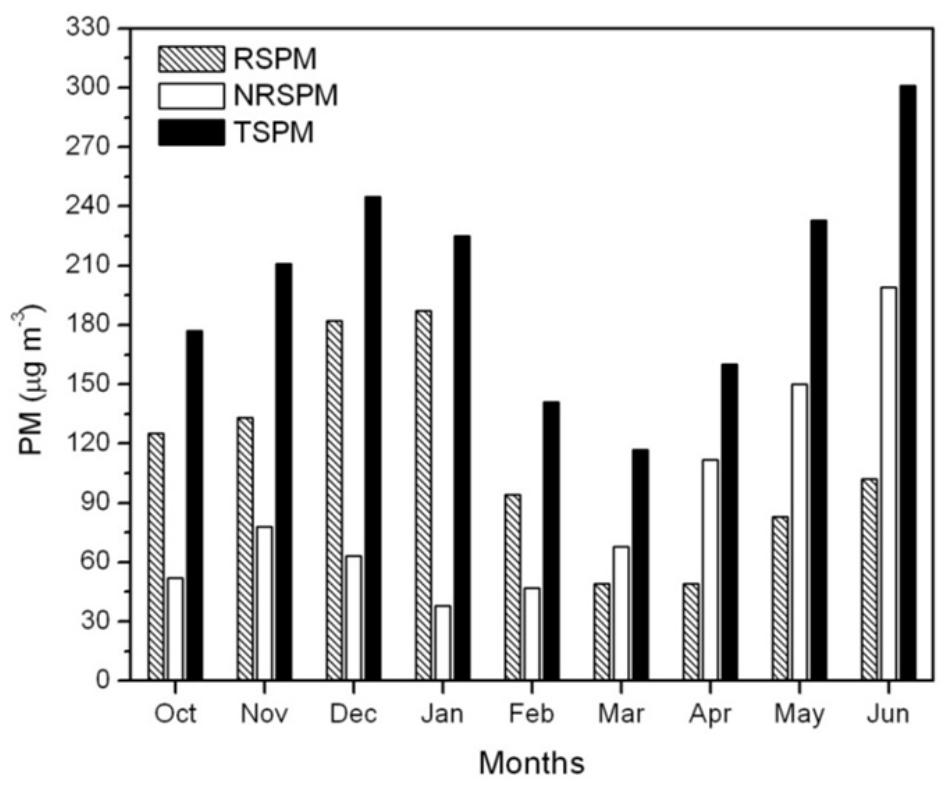

Fig. 1. Temporal variation of respirable (RSPM), non-respirable (NRSPM) and total suspended particulate matter (TSPM) over study region during October, 2013 to June, 2014.
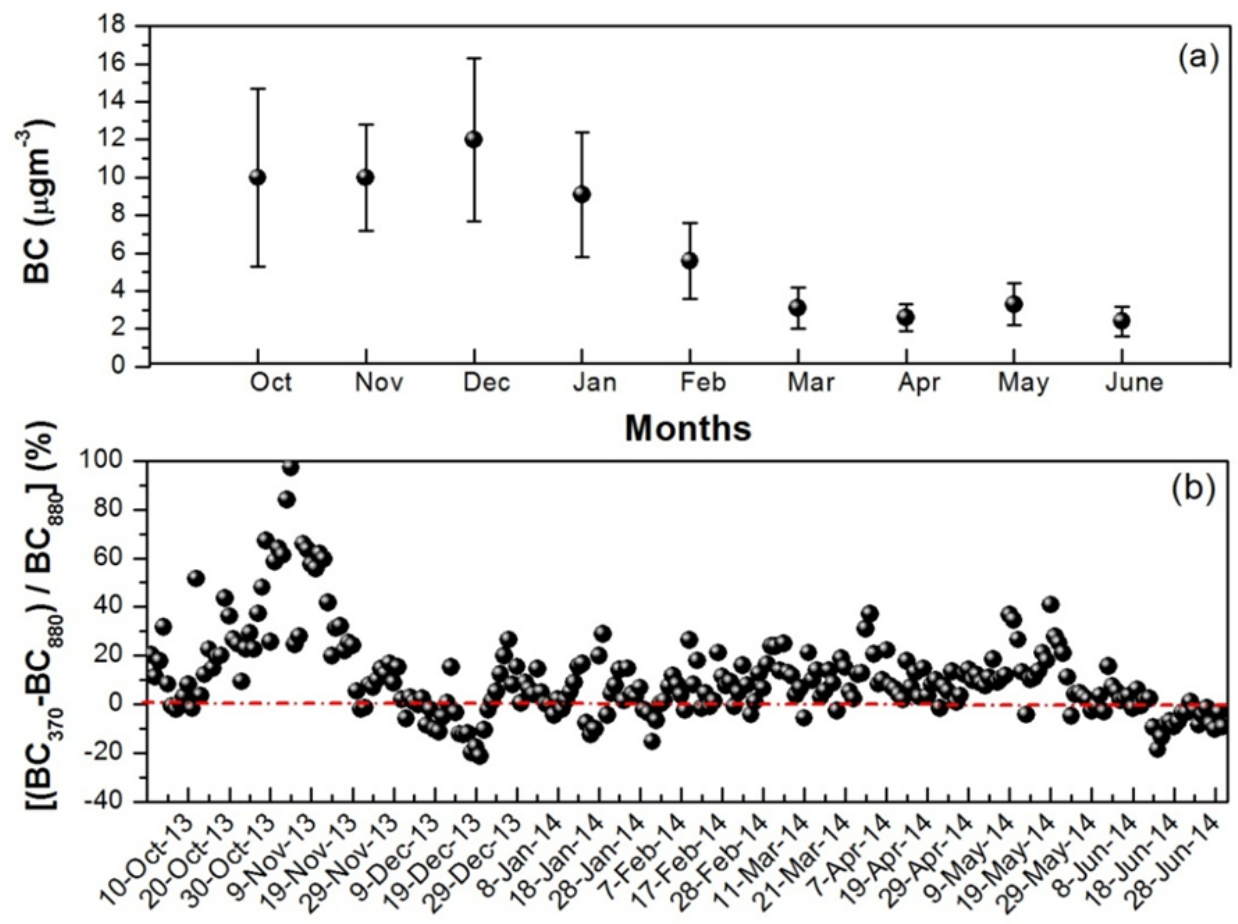

Dates

Fig. 2. Temporal variation in (a) monthly mean mass concentration of $\mathrm{BC}$ and (b) percentage contribution of $\mathrm{BC}$ measured at $370 \mathrm{~nm}$ and $880 \mathrm{~nm}$ for source apportionment.

February whereas it shows weak wavelength dependence from April to June except during May (Fig. 3). Furthermore, the spectral AOD was used to derive the Ångström exponent $(\mathrm{AE} ; \alpha)$ in the wavelength range of $380-870 \mathrm{~nm}$. The average value of $\mathrm{AE}$ provides valuable information about particles size distribution. High value of $\mathrm{AE}$ represents the dominance of fine-mode aerosol particles and vice-versa (Eck et al., 1999). The average value of AE is found to be close to unity from October to February, indicating the predominance of fine-mode particles due to high anthropogenic activities (paddy residue burning, bioand fossil fuel combustion) whereas it varied from 0.5 to 0.7 during March to June except in May (0.9), showing relative dominance of coarse-mode particles (dust aerosol) (Table 1). High value of AE during May can be attributed to wheat residue burning over the study region. In general, 


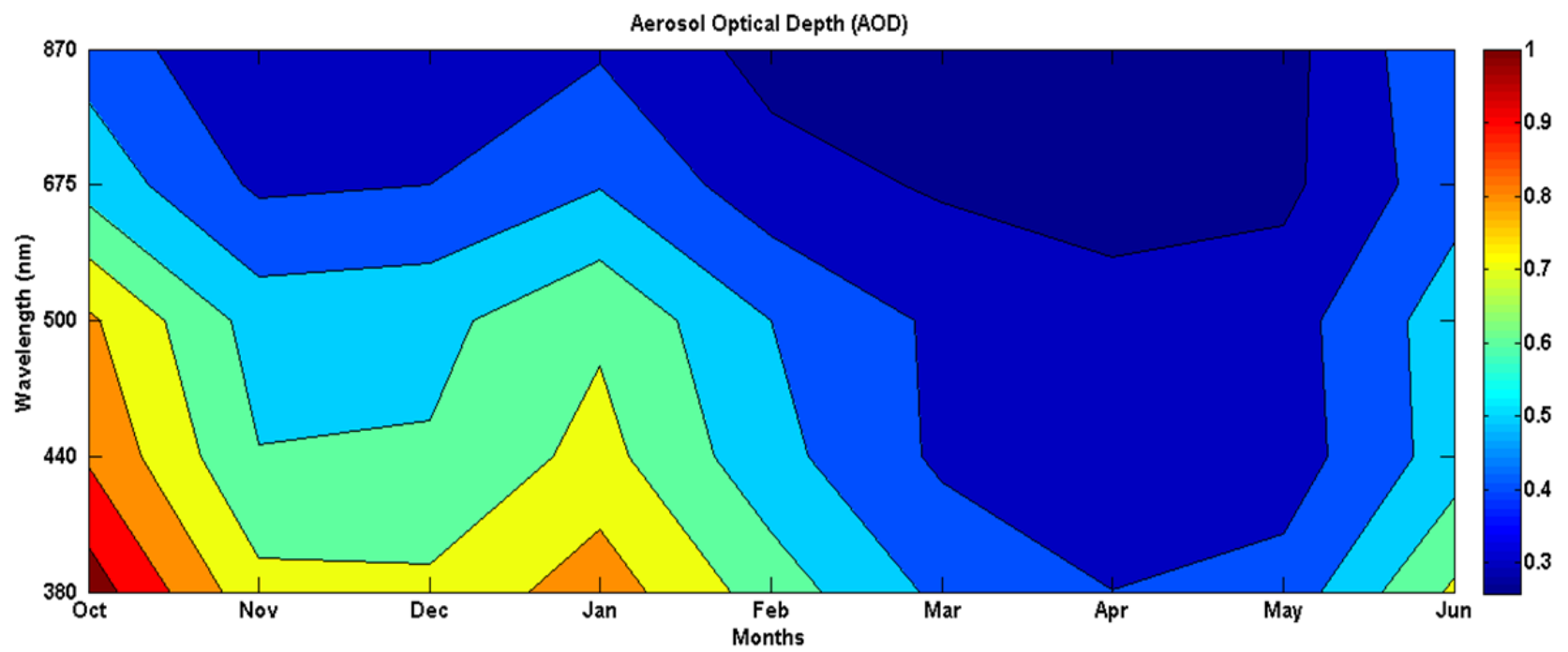

Fig. 3. Variation in monthly mean spectral AOD during October, 2013 to June 2014.

the fine-mode particles are dominant from October to February and coarse-mode particles from March to June over the study region. The same trend is reflected in the mass concentration of RSPM and NRSPM as discussed earlier. SSA is considered as one of the crucial parameter among other optical parameters in forcing calculations as it is measure of the ratio of scattering coefficient to total extinction (Satheesh et al., 2010). OPAC simulated $\mathrm{SSA}_{500}$ ranged between 0.890 and 0.947 having highest value during June and lowest during the months of December and January (Fig. 4). The magnitude of $\mathrm{SSA}_{500}$ during October to January is found to be $\leq 0.898 \pm 0.004$ while it is $\geq 0.900 \pm 0.021$ during February to June. Low value of SSA during December and January is attributed to high BC mass mixing ratio of $\sim 4 \%$ while it ranges only between 0.6 and $3.1 \%$ during February to June. Spectral SSA variation shows that it is wavelength dependent and decreases with wavelength during October to March whereas it increases with wavelength during April to June (Fig. 4). This difference in wavelength dependence is attributed to the relative dominance of fine- and coarse-mode particles during the study period. During October to March, SSA decreases with wavelength indicating the dominance of fine-mode particles while it increases with wavelength during April to June due to dominance of coarse-mode particles (Dey et al., 2004; Tiwari et al., 2013).

\section{Clear-Sky Radiative Properties of Composite and BC Aerosol}

Earlier studies show that aerosol loading affects the weather and climate pattern by perturbing the earth's radiation budget over any region which can be understood by estimating the aerosol direct radiative forcing. The magnitude of aerosol radiative forcing (ARF) further depends upon various factors such as SSA, AOD, asymmetric parameter, surface albedo and prevailing meteorological conditions. In addition, atmospheric loading of highly absorbing soot and some of the mineral aerosol also affect both magnitude and sign of ARF by modifying the SSA value of composite aerosol
(Satheesh et al., 2010). Clear-sky direct ARF due to composite aerosols at top of the atmosphere (TOA), at the surface (SRF) and in the atmosphere (ATM) under clear sky-conditions estimated using SBDART model has been presented in Fig. 5. The magnitude of clear-sky ARF at SRF varied from -21.1 to $-47.3 \mathrm{Wm}^{-2}$ during October to June with highest magnitude during October and lowest during April. It is well understood that SRF value always remains negative since the combined effect of absorption and scattering due to composite aerosol result in attenuation of the surface reaching solar radiation. In the present study, the attenuation of surface reaching flux is higher by $\sim 30 \%$ during October to February than during April to June. This can be attributed to relatively higher aerosol loading from October to February than from April to June. On the other hand, the value of clear-sky ARF at TOA remained negative during October to June with magnitude ranged between -6.4 and $-12.3 \mathrm{Wm}^{-2}$. The sign of TOA forcing depends upon difference in the amount of radiation backscattered by aerosol free atmosphere and aerosol loaded atmosphere. In the present study, negative value of TOA forcing has been observed implying more radiation lost to space due to enhanced backscattering of radiation by aerosol than aerosol free atmosphere that may result in cooling of the earthatmosphere system. The value of clear-sky direct atmospheric aerosol radiative forcing (ATM) varied from +12.4 to $+35.9 \mathrm{Wm}^{-2}$ during October to June and corresponding atmospheric heating rate in the lower atmosphere varies from 0.35 to $1.01 \mathrm{~K} \mathrm{day}^{-1}$. Attempt was also made to infer the ARF due to BC aerosols only using SBDART model as presented in Fig. 6. The magnitude of ARF at SRF varied from -9.0 to $-27.6 \mathrm{Wm}^{-2}$ while atmospheric aerosol radiative forcing (ATM) varied from +11.4 to $+35.1 \mathrm{Wm}^{-2}$ during the study period. However, ARF at TOA remained positive throughout the study period and varied from +2.4 to $+7.5 \mathrm{Wm}^{-2}$ indicating the absorbing nature of $\mathrm{BC}$. The contribution of climatic forcing agent $\mathrm{BC}$ to net aerosol radiative forcing due to composite aerosols has been quantified and found that even though the fraction of $\mathrm{BC}$ to 


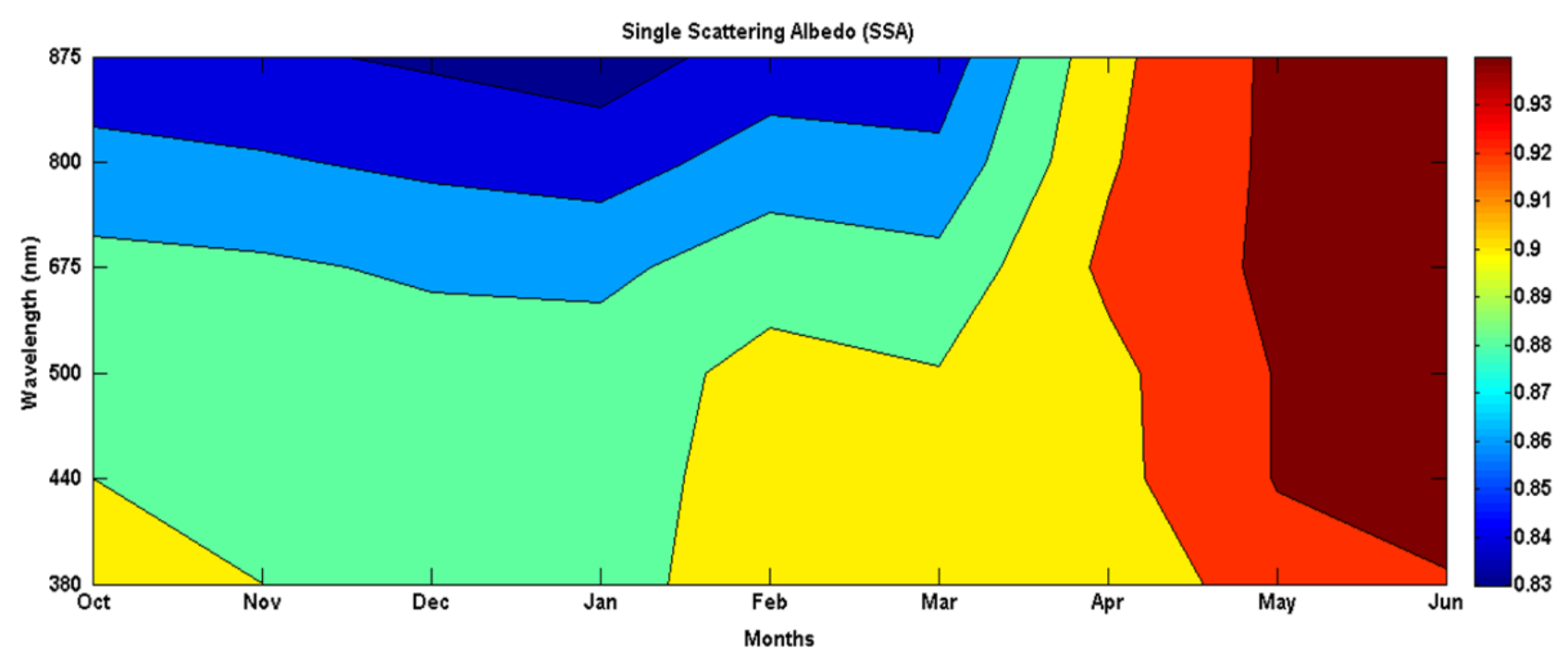

Fig. 4. Variation of OPAC simulated spectral single scattering albedo during October, 2013 to June, 2014.

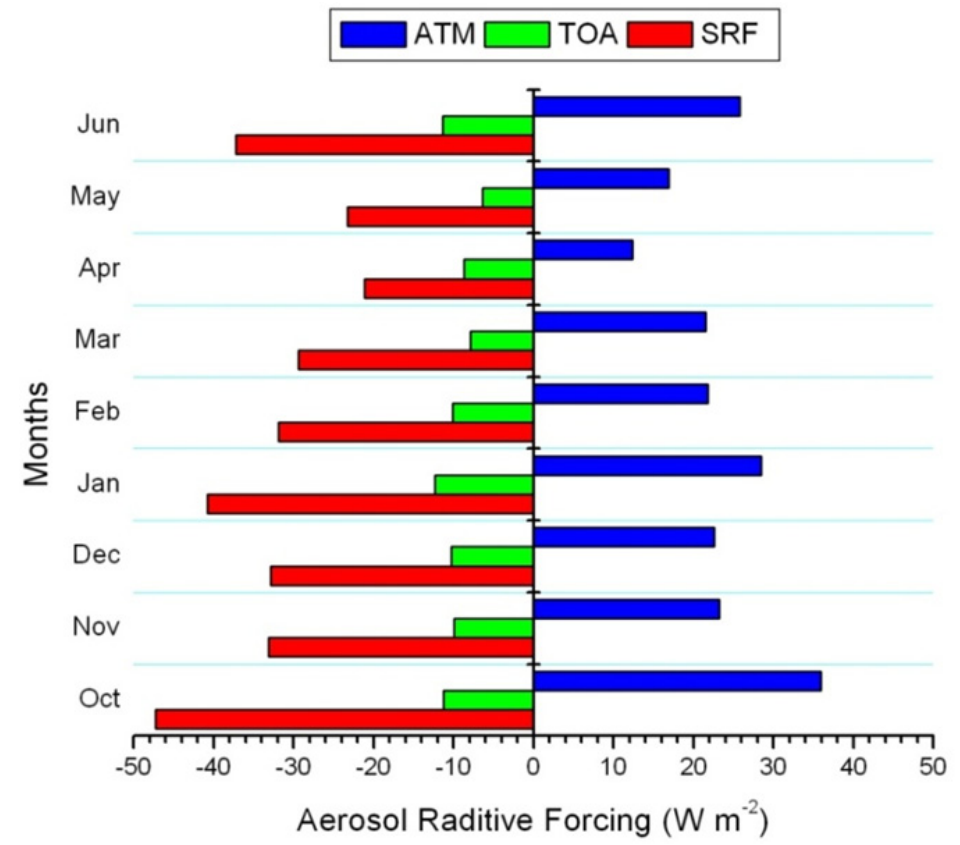

Fig. 5. Temporal variation of Aerosol Radiative Forcing (ARF) in the atmosphere (ATM), at Top of the Atmosphere (TOA) and at Surface (SRF) due to composite aerosols.

composite aerosols is marginal but their effect on net clearsky ATM ARF is significant. Clear-sky TOA ARF is positive in the case of $\mathrm{BC}$ aerosol which are highly absorbing in nature and produced negative surface forcing which is around $44 \%$ of the net clear-sky SRF due to composite aerosol. $\mathrm{BC}$ mass concentration contribute only $2.4 \%$ (period average) to the composite aerosol but its contribution to net clear-sky ATM ARF is more than $60 \%$ throughout the observation period (Fig. 7). Atmospheric heat rate due to $\mathrm{BC}$ alone is computed and it varied from 0.32 to $0.98 \mathrm{~K} \mathrm{day}^{-1}$ during the study period. Overall, heating rate due to $\mathrm{BC}$ alone is found to be $\sim 80 \%$ of the total heating rate of composite aerosols, suggesting that black carbon aerosol contribute significantly to the atmospheric warming on the regional scale. In a similar study, Ramachandran et al. (2012) reported that percentage contribution of BC to net clear-sky ATM $\mathrm{ARF}$ is more than $65 \%$ over an urban location in India while BC contribute only 2 to $7 \%$ to the total aerosol mass. Similarly, Panicker et al. (2010) also reported the percentage contribution of BC to net clear-sky ATM ARF around 55\% over Pune, India, even though the mass mixing ratio of $\mathrm{BC}$ ranged from 2.2 to $6 \%$.

\section{Black Carbon and Climate Change}

Recent studies throughout the globe have identified various regional hot spots of $\mathrm{BC}$ induced atmospheric heating and IGP is one of them (Ramanathan et al., 2007). Higher concentration of $\mathrm{BC}$ over these regions reduced 


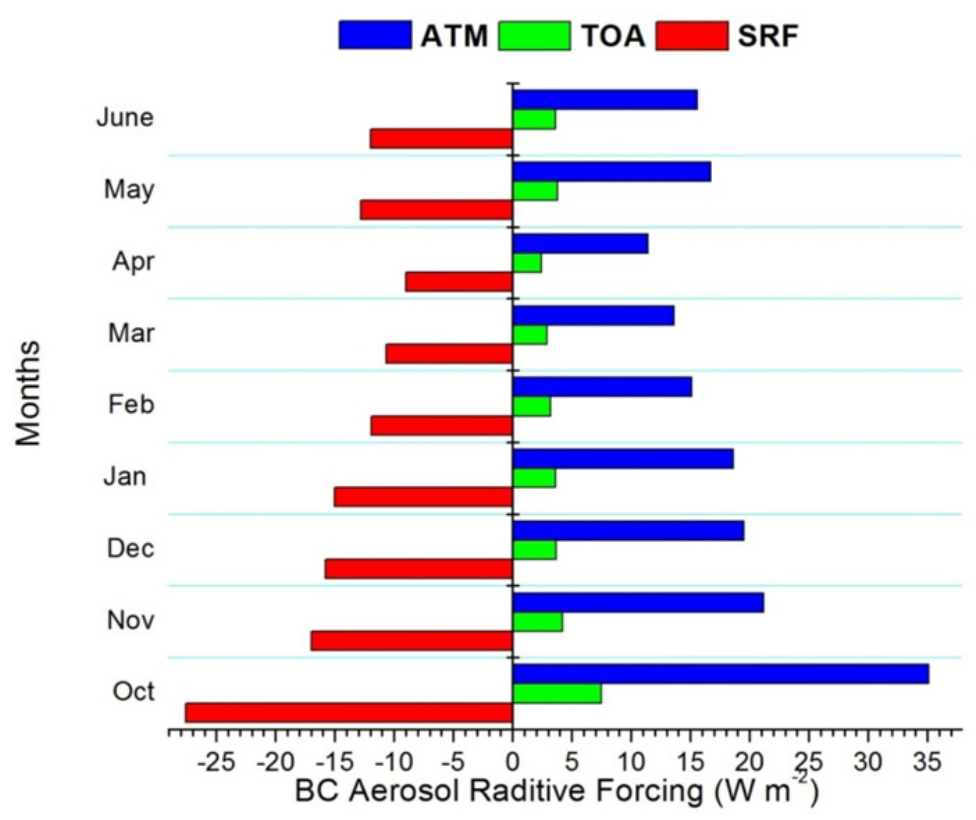

Fig. 6. Temporal variation of Aerosol Radiative Forcing (ARF) in the atmosphere (ATM), at Top of the Atmosphere (TOA) and at Surface (SRF) due to BC aerosols.

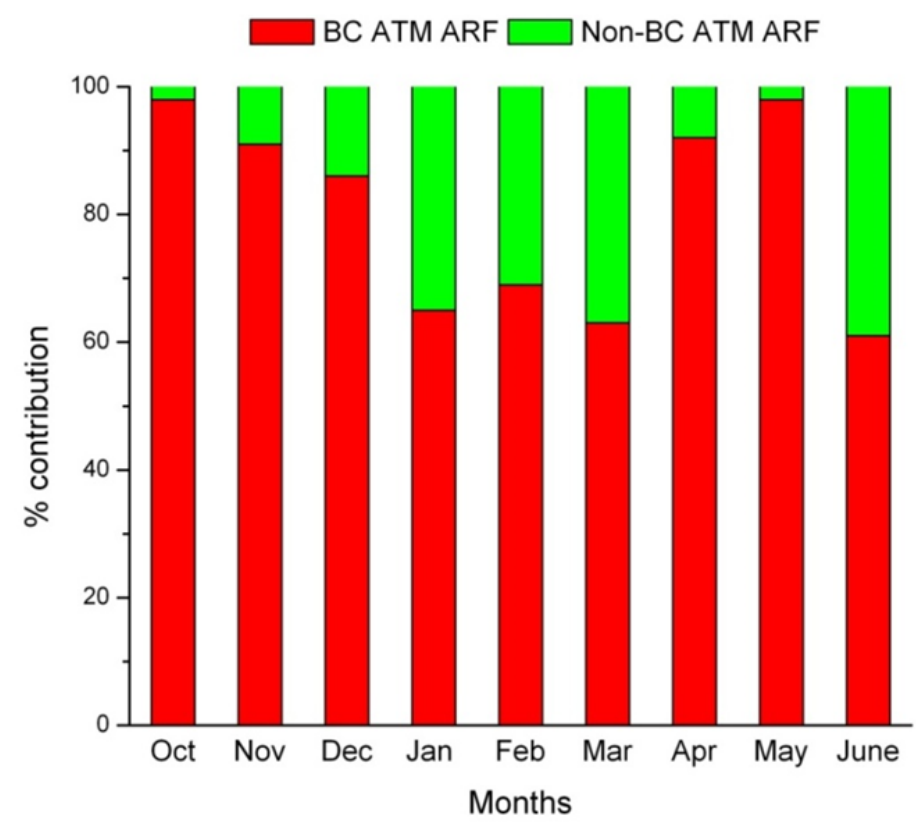

Fig. 7. Contribution of BC Aerosol Radiative Forcing (ARF) in the atmosphere (ATM) to net atmospheric (ATM) aerosol radiative forcing (ARF) of composite aerosols.

surface reaching solar flux due to absorption of direct solar radiation which leads to surface dimming. Same has been found in the present study as BC produced negative forcing and its contribution is about $\sim 44 \%$ to total surface forcing of composite aerosol. In the present analysis, strong atmospheric heating along with surface dimming due to $\mathrm{BC}$ could intensify the low-level inversion, which slowdown the convection and inhibit cloud formation, thereby leading to weaker hydrological cycle (Ramachandran et al., 2012, and references therein). Evidence of weakening the monsoon over the study region due to surface dimming were reported by various researchers (Ramanathan and Carmichael, 2008, and references therein). $\mathrm{BC}$ aerosol interacts with climate system in a very complex way as other than the direct and indirect effects of $\mathrm{BC}$, there is semi-direct effect too. During enhanced BC concentration in clouds, solar heating could lead to fast evaporation of cloud droplets. This leads to less cloud fraction and low albedo resulting in enhanced positive climate forcing due to BC. However, the magnitude of semi-direct effects is highly uncertain. There are many other pathways through which $\mathrm{BC}$ interact with the climate system. In this context, the important question is: Can we 
slow down the rate of climate change by reducing the emission of BC? The answer is "Yes," as greenhouse gases have long residence time in the atmosphere. On the other hand, $\mathrm{BC}$ aerosol have only a few days' residence time in the atmosphere, hence limiting $\mathrm{BC}$ emissions offers an opportunity to mitigate the effects of global warming trends over the short-term basis (Bond et al., 2013). Other factor that is important from forcing point of view and needs to be considered is that sources emitted pure $\mathrm{BC}$ produces more positive forcing than the sources producing high $\mathrm{OC} / \mathrm{BC}$ ratio (Kopp and Mauzerall, 2010). The present study region is characterized by high $\mathrm{OC} / \mathrm{BC}$ (or EC) ratio due to largescale agricultural waste and bio-fuel burning (Singh et al., 2014; Rastogi et al., 2016). Thus, in the context of climatic prospective, controlling the fossil fuel combustion over the study region will have more impact on limiting the regional atmospheric warming than due to biomass burning.

\section{SUMMARY AND CONCLUSIONS}

The present study reported the clear-sky direct aerosol radiative forcing of composite and black carbon aerosol over Patiala, a site located in the northwestern part of the Indo-Gangetic Plain, from October 2013 to June 2014. A high mass fraction of RSPM along with high values for the Ångström exponent $\left(\alpha_{380-870}\right)$ from October to February indicates the dominance of fine-mode particles during this period over the study region. On the other hand, the climate forcing agent $\mathrm{BC}$ showed a higher mass concentration (9.4 $\pm 4.1 ; \pm 1 \sigma$ ) from October to February than from March to June $(2.9 \pm 1.0)$, a trend attributed to the predominant emissions from biomass/biofuel burning during autumn and winter. The OPAC simulated $\mathrm{SSA}_{500}$ exhibited relatively low values $(\leq 0.898)$ from October to January compared to the rest of the study period $(\geq 0.900)$ due to a high $\mathrm{BC}$ mass mixing ratio from during October to January over the study region. The SBDRAT estimated clear-sky direct atmospheric aerosol radiative forcing varied from +12 to $+36 \mathrm{Wm}^{-2}$, resulting in an atmospheric heating rate in the lower atmosphere of 0.35 to $1.01 \mathrm{~K} \mathrm{day}^{-1}$. However, despite numerous researchers reporting values for the clear-sky direct aerosol radiative forcing, uncertainty still exists in quantifying the total anthropogenic climatic forcing. This uncertainty is mainly attributed to the indirect aerosol radiative forcing in addition to the error associated with the estimation of clear-sky direct forcing. The mean global radiative forcing, which is based on a combination of aerosol-radiation interaction (direct) and aerosol-cloud interaction (indirect), excluding $\mathrm{BC}$ on snow or ice, is estimated to be $-0.9 \mathrm{Wm}^{-2}$ (the uncertainty in the estimation is $\sim 5-95 \%$ ), with the contribution of direct radiative forcing being $-0.35 \mathrm{Wm}^{-2}$ (IPCC, 2013). Inaccuracies in determining the indirect aerosol effect on radiative forcing are due to a lack of fine tuning in the modeling of cloud macrophysics. Thus, future studies should focus on improving the simulation of cloud macrophysics and their accurate parameterization in global models in order to accurately predict anthropogenic climatic forcing.

The contribution of the climatic forcing agent $\mathrm{BC}$ to the net radiative aerosol forcing has been quantified. Even though the average mass fraction of $\mathrm{BC}$ in the total aerosol loading was marginal $(2.4 \%)$ throughout the study period, its contribution to the net clear-sky atmospheric aerosol radiative forcing was very significant $(>60 \%)$, indicating that it contributes significantly to atmospheric warming on a regional scale. The present study reveals that composite and $\mathrm{BC}$ aerosol radiative forcing has the potential to affect the regional climate, suggesting that effective mitigation strategies must be adopted in order to minimize their impact on climate forcing.

\section{ACKNOWLEDGEMENT}

The present study was carried out under ISRO-GBP (ARFI) research project and authors are grateful to ISRO for financial support. The meteorological data for Patiala station provided by IMD is duly acknowledged. The authors are grateful to the anonymous reviewer for constructive comments and suggestions to improve the manuscript.

\section{REFERENCES}

Bond, T.C., Doherty, S.J., Fahey, D.W., Forster, P.M., Berntsen, T., DeAngelo, B.J., Flanner, M.G., Ghan, S., Kärcher, B., Koch, D., Kinne, S., Kondo, Y., Quinn, P.K., Sarofim, M.C., Schultz, M.G., Schulz, M., Venkataraman, C., Zhang, H., Zhang, S., Bellouin, N., Guttikunda, S.K., Hopke, P.K., Jacobson, M.Z., Kaiser, J.W., Klimont, Z., Lohmann, U., Schwarz, J.P., Shindell, D., Storelvmo, T., Warren, S.G. and Zender, C.S. (2013). Bounding the role of black carbon in the climate system: A scientific assessment. J. Geophys. Res. 118: 5380-5532.

Dey, S., Tripathi, S.N. and Singh, R.P. (2004). Influence of dust storms on the aerosol optical properties over the Indo-Gangetic basin. J. Geophys. Res. 109: D20211.

Dey, S., Tripathi, S.N. and Mishra, S.K. (2008). Probable mixing state of aerosols in the Indo-Gangetic Basin, northern India. Geophys. Res. Lett. 35: L03808.

Eck, T.F., Holben, B.N., Reid, J.S., Dubovic, O., Smirnov, A., O’Neil, N.T., Slutsker, I. and Kinne, S. (1999). Wavelength dependence of the optical depth of biomass burning, urban and desert dust aerosols. J. Geophys. Res. 104: 349 .

Hansen, A.D.A. (2005). Manual of the aethalometer. Magee Scientific, Berkeley, California, USA.

Herich, H., Hueglin, C. and Buchmann, B. (2011). A 2.5 year's source apportionment study of black carbon from wood burning and fossil fuel combustion at urban and rural sites in Switzerland. Atmos. Meas. Tech. 4: 14091420 .

Hess, M., Koepke, P. and Schultz, I. (1998). Optical properties of aerosols and clouds: The software package OPAC. Bull. Am. Meteorol. Soc. 9: 831-844.

IPCC, Climate Change (2013). Contribution of Working Group I to the Fifth Assessment Report of the Intergovernmental Panel on Climate Change. The Physical Science Basis. Cambridge University Press, 
Cambridge, United Kingdom and New York, NY, USA.

Kant, Y., Singh, A., Mitra, D., Singh, D., Srikanth, P., Madhusudanacharyulu, A.S. and Krishna Murthy, Y.V.N. (2015). Optical and radiative properties of aerosol over two locations in the North-west part of India during premonsoon season. Adv. Meteorol. 2015: 517434.

Kaskaoutis, D.G., Kumar, S., Sharma, D., Singh, R.P., Kharol, S.K., Sharma, M., Singh, A.K., Singh, S., Singh, A. and Singh, D. (2014). Effects of crop residue burning on aerosol properties, plume characteristics, and long range transport over northern India. J. Geophys. Res. 119: 5424-5444.

Kedia, S. and Ramachandran, S. (2011). Seasonal variations in aerosol characteristics over an urban location and a remote site in western India. Atmos. Environ. 45: 21202128.

Kopp, R.E. and Mauzerall, D.L. (2010). Assessing the climatic benefits of black carbon mitigation. Proc. Natl. Acad. Sci. U.S.A. 107: 11703-11708.

Lau, K-M., Kim, M.K. and Kim, K.M. (2006). Asian summer monsoon anomalies induced by aerosol direct forcing: The role of the Tibetan Plateau. Clim. Dyn. 26: 855-864.

Liou, K.N. (2002). An introduction to atmospheric radiation. Elsevier, New York, 583.

Morys, M., Mims III F.M., Hagerup, S., Anderson, S.E., Backer, A., Kia, J. and Walkup, T. (2001). Design, calibration and performance of Microtops II hand-held ozone monitor and sun photometer. J. Geophys. Res. 106: 14573-14582.

Panicker, A.S., Pandithurai, G., Safai, P.D., Dipu, S. and Lee, D.I. (2010). On the contribution of black carbon to the composite aerosol radiative forcing over an urban environment. Atmos. Environ. 40: 3066-3070.

Rajput, P., Sarin, M.M., Rengarajan, R. and Singh, D. (2011).Atmospheric polycyclic aromatic hydrocarbons (PAHs) from post-harvest biomass burning emissions in the Indo-Gangetic Plain: Isomer ratios and temporal trends. Atmos. Environ. 45: 6732-6740.

Ramachandran, S., Srivastava, R., Kedia, S. and Rajesh, T.A. (2012). Contribution of natural and anthropogenic aerosols to optical properties and radiative effects over an urban location. Environ. Res. Letts. 7: 034028.

Ramanathan, V., Li, F., Ramana, M.V., Praveen, P.S., Kim, D., Corrigan, C.E., Nguyen, H., Stone, E.A., Schauer, J.J., Carmichael, G.R., Adhikary, B. and Yoon, S.C. (2007). Atmospheric brown clouds: Hemispherical and regional variations in long-range transport, absorption, and radiative forcing. J. Geophys. Res. 112: D22S2.

Ramanathan, V. and Carmichael, G. (2008). Global and regional climate change due to black carbon. Nat. Geosci. 1: 221-227.

Rastogi, N., Patel A., Singh, A. and Singh, D. (2015). Diurnal variability in secondary organic aerosol formation over Indo-Gangetic Plain during winter using online measurement of water-soluble organic carbon. Aerosol Air Qual. Res. 15: 2225-2231.

Rastogi, N., Singh, A., Singh, D. and Sarin, M.M. (2014). Chemical characterization of $\mathrm{PM}_{2.5}$ at a source region of biomass burning emissions: Evidence for secondary aerosol formation. Environ. Pollut. 184: 563-569.

Rastogi, N., Singh, A., Sarin, M.M. and Singh, D. (2016). Temporal variability of primary and secondary aerosols over northern India: Impact of biomass burning emissions. Atmos. Environ. 125: 396-403.

Ricchiazzi, P., Yang, S., Gautier, C. and Sowle, D. (1998). SBDART: A research and teaching software tool for plane-parallel radiative transfer in the Earth's atmosphere. Bull. Amer. Meteoro. Soc. 79: 2101-2114.

Sahai, S., Sharma, C., Singh, D.P., Dixit, C.K., Singh, N., Sharma, P., Singh, K., Bhatt, S., Ghude, S., Gupta, V., Gupta, R.K., Tiwari, M.K., Garg, S.C., Mitra, A.P. and Gupta, P.K. (2007). A study for development of emission factors for trace gases and carbonaceous particulate species from in situ burning of wheat straw in agricultural fields in India. Atmos. Environ. 41: 9173-9186.

Satheesh, S.K., Vinoj, V. and Moorthy, K.K. (2010). Radiative effects of aerosols at an urban location in southern India: Observations versus model. Atmos. Environ. 44: 5295-5304.

Sharma, D., Singh, D. and Kaskaoutis, D.G. (2012a). Impact of two intense dust storms on aerosol characteristics and radiative forcing over Patiala, northwestern India. $A d v$. Meteorol. 2012: 956814.

Sharma, D., Singh, D. and Sumit, D. (2012b). Case studies of black carbon aerosol characteristics during agriculture crop residue burning period over Patiala, Punjab, India using the synergy of ground based and satellite observations. Int. J. Geol. Earth Environ. Sci. 2: 315-326.

Singh, A., Rajput, P., Sharma, D., Sarin, M.M. and Singh, D. (2014). Black carbon and elemental carbon from postharvest agricultural-waste burning emissions in the Indo-Gangetic Plain. Adv. Meteorol. 2014: 179301.

Singh, A., Rastogi, N., Sharma, D. and Singh, D. (2015). Inter and intra-annual variability in aerosol characteristics over northwestern Indo-Gangetic Plain. Aerosol Air Qual. Res. 15: 376-386.

Singh, A., Rastogi, N., Patel, A. and Singh, D. (2016a). Seasonality in size-segregated ionic composition of ambient particulate pollutants over Indo-Gangetic Plain: Source apportionment using PMF. Environ. Pollut. 219: 906-915.

Singh, A., Tiwari, S., Sharma, D., Singh, D., Tiwari, S., Srivastava, A.K., Rastogi, N. and Singh, A.K. (2016b). Characterization and radiative impact of dust aerosols over northwestern part of India: A case study during a severe dust storm. Meteorol. Atmos. Phys. 128: 779-792.

Singh, A., Srivastava, R., Rastogi, N. and Singh, D. (2016c). Absorbing and scattering aerosols over the source region of biomass burning emissions: Implications in the assessment of optical and radiative properties. Atmos. Environ. 127: 61-68.

Srivastava, R., Ramachandran, S., Rajesh, T.A. and Kedia, S. (2011). Aerosol radiative forcing deduced from observations and models over an urban location and sensitivity to single scattering Albedo. Atmos. Environ. 45: 6167-6171.

Tare, V., Tripathi, S.N., Chinnam, N., Srivastava, A.K., Dey, 
S., Manar, M., Kanawade, V.P., Agarwal, A., Kishore, S., Lal, R.B. and Sharma, M. (2006). Measurements of atmospheric parameters during Indian Space Research Organization-Geosphere Biosphere Program Land Campaign II at a typical location in the Ganga Basin: 2. Chemical properties. J.Geophys. Res. 111: D23210.

Tiwari, S., Srivastava, A.K. and Singh, A.K. (2013). Heterogeneity in pre-monsoon aerosol characteristics over the Indo-Gangetic Basin. Atmos. Environ. 77: 738747.
Wang, M., Ghan, S., Ovchinnikov, M., Liu, X., Easter, R., Kassianov, E., Qian, Y. and Morrison, H. (2011). Aerosol indirect effects in a multi-scale aerosol-climate model PNNL-MMF. Atmos. Chem. Phys. 11: 5431-5455.

Received for review, September 28, 2017

Revised, March 20, 2018

Accepted, May 30, 2018 